\title{
Copeptin as a marker of outcome after cardiac arrest: a sub-study of the TTM trial
}

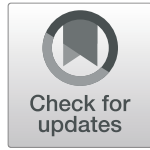

Joachim Düring ${ }^{1 *}$, Martin Annborn², Tobias Cronberg ${ }^{3}$, Josef Dankiewicz ${ }^{4}, Y_{v a n}$ Devaux ${ }^{5}$, Christian Hassager ${ }^{6}$, Janneke Horn ${ }^{7}$, Jesper Kjaergaard ${ }^{6}$, Michael Kuiper ${ }^{8}$, Homa Rafi Nikoukhah $^{9}$, Pascal Stammet ${ }^{10}$, Johan Undén ${ }^{11}$, Michael Jaeger Wanscher ${ }^{12}$, Matt Wise ${ }^{13}$, Hans Friberg $^{1}$ and Niklas Nielsen ${ }^{2}$

\begin{abstract}
Background: Arginine vasopressin has complex actions in critically ill patients, involving vasoregulatory status, plasma volume, and cortisol levels. Copeptin, a surrogate marker for arginine vasopressin, has shown promising prognostic features in small observational studies and is used clinically for early rule out of acute coronary syndrome. The objective of this study was to explore the association between early measurements of copeptin, circulatory status, and short-term survival after out-of-hospital cardiac arrest.
\end{abstract}

Methods: Serial blood samples were collected at 24,48 , and $72 \mathrm{~h}$ as part of the target temperature management at $33^{\circ} \mathrm{C}$ versus $36^{\circ} \mathrm{C}$ after cardiac arrest trial, an international multicenter randomized trial where unconscious survivors after out-of-hospital cardiac arrest were allocated to an intervention of 33 or $36^{\circ} \mathrm{C}$ for $24 \mathrm{~h}$. Primary outcome was 30-day survival with secondary endpoints circulatory cause of death and cardiovascular deterioration composite; in addition, we examined the correlation with extended the cardiovascular sequential organ failure assessment (eCvSOFA) score.

Results: Six hundred ninety patients were included in the analyses, of whom 203 (30.3\%) developed cardiovascular deterioration within $24 \mathrm{~h}$, and 273 (39.6\%) died within 30 days. Copeptin measured at $24 \mathrm{~h}$ was found to be independently associated with 30-day survival, hazard ratio 1.17 [1.06-1.28], $p=0.001$; circulatory cause of death, odds ratio 1.03 [1.01-1.04], $p=0.001$; and cardiovascular deterioration composite, odds ratio of $1.05[1.02-1.08], p<0.001$. Copeptin at $24 \mathrm{~h}$ was correlated with eCvSOFA score with rho 0.19 [0.12-0.27], $p<0.001$.

Conclusion: Copeptin is an independent marker of severity of the post cardiac arrest syndrome, partially related to circulatory failure.

Trial registration: Clinical Trials, NCT01020916. Registered November 26, 2009.

Keywords: Humans, Copeptin, Arginine vasopressin, AVP protein human, Out-of hospital cardiac arrest, Biomarkers, Critical illness, Prognosis, Survivors

\footnotetext{
* Correspondence: joachim.during@gmail.com

'Department of Clinical Sciences, Anesthesia \& Intensive care, Lund University, Skåne University Hospital, Malmö, Sweden

Full list of author information is available at the end of the article
}

(C) The Author(s). 2020 Open Access This article is licensed under a Creative Commons Attribution 4.0 International License, which permits use, sharing, adaptation, distribution and reproduction in any medium or format, as long as you give appropriate credit to the original author(s) and the source, provide a link to the Creative Commons licence, and indicate if changes were made. The images or other third party material in this article are included in the article's Creative Commons. licence, unless indicated otherwise in a credit line to the material. If material is not included in the article's Creative Commons licence and your intended use is not permitted by statutory regulation or exceeds the permitted use, you will need to obtain permission directly from the copyright holder. To view a copy of this licence, visit http://creativecommons.org/licenses/by/4.0/ The Creative Commons Public Domain Dedication waiver (http://creativecommons.org/publicdomain/zero/1.0/) applies to the data made available in this article, unless otherwise stated in a credit line to the data. 


\section{Introduction}

Hypoxic ischemic encephalopathy (HIE) is the major determinant of outcome after out-of-hospital cardiac arrest (OHCA) [1]. Existing prognostication models are targeted at neurologic functional outcome. Death is biphasic after OHCA with early death (1-3 days) to a large degree related to circulatory failure, while later death (> 3 days) is mainly related to withdrawal of life-sustaining therapy (WLST) due to assumed severe HIE [2]. Patients with a presumed high risk of circulatory-related death may therefore benefit from extended hemodynamic monitoring and support. This is particularly relevant for patients without signs of severe HIE and a potential good long-term outcome. A risk stratification model addressing this topic has recently been presented but did not include the use of biomarkers [3].

Arginine vasopressin (AVP) is a peptide hormone released from the posterior pituitary gland that increases solute-free water reabsorption in the renal tubules and systemic vascular resistance by constricting selected arterioles. Elevated AVP levels have been shown to correlate with shock [4] and cardiovascular failure [5-7]. Measurement of AVP is challenging because of its short half-life, but it can be replaced by measurement of copeptin (also known as CT-proAVP), the C-terminal proteolytic product of the pre-pro-hormone of AVP. Copeptin has shown to be a reliable surrogate biomarker of vasopressin [8], and levels are significantly increased at hospital admission in patients with acute coronary syndrome [9]. Also, high copeptin levels are associated with risk of death in patients with cardiovascular failure $[10,11]$ while low levels have been implemented in clinical practice to rule out non-ST-segment acute myocardial infarction [9, 12]. Furthermore, copeptin has been suggested as a promising prognostic biomarker after OHCA [13-16]. It is unknown whether the prognostic capabilities of AVP/copeptin are related to cardiovascular failure alone or if copeptin is merely a marker of disease severity. The aim of this exploratory study was to investigate the relationship between early copeptin levels, circulatory failure, and mortality in the setting of OHCA. We hypothesized that (1) early copeptin levels are associated with early mortality and (2) copeptin levels are associated with circulatory failure.

\section{Materials and methods}

\section{Study design and setting}

This is a predefined biomarker sub-study of the target temperature management (TTM) $33^{\circ} \mathrm{C}$ versus $36^{\circ} \mathrm{C}$ after out-of-hospital cardiac arrest trial [17], randomizing 950 unconscious $\mathrm{OHCA}$ patients to an intervention of $33^{\circ} \mathrm{C}$ or $36^{\circ} \mathrm{C}$, indicating no significant benefit of a target temperature of $33^{\circ} \mathrm{C}$ compared to $36^{\circ} \mathrm{C}$ [17]. The trial protocol was approved by ethical committees in each participating country, and informed consent was waived or obtained from all participants or relatives according to national legislation, in line with the Helsinki declaration [18].

\section{Study population}

Unconscious adult patients were included in the TTM trial within $4 \mathrm{~h}$ of return of stable spontaneous circulation (ROSC) after OHCA of a presumed cardiac cause. Previous medical history was recorded without no strict definitions. Patient hemodynamics at screening and before randomization were classified in one of three categories: 1, no shock, systolic blood pressure (SBP) $>90$ mmHg; 2, moderate shock, SBP $<90 \mathrm{mmHg}$ for $>30$ min, or the need of supportive measures (fluid loading, vasopressor, and/or inotropic support) to maintain SBP $>90 \mathrm{mmHg}$ and/or end-organ hypoperfusion (cool extremities, urine output $<30 \mathrm{ml} / \mathrm{h}$ ); and 3 , severe shock, SBP $<80 \mathrm{mmHg}$ in spite of supportive measures (medical and mechanical) that could not be reversed within the inclusion window. Patients in persistent severe shock were not eligible. Of the 36 study sites, seven sites did not participate in the biobank sub-study due to legal or logistical reasons. This analysis included all patients alive at $24 \mathrm{~h}$ with at least one recorded copeptin level during the sampling period.

\section{Sampling and measurements}

Blood serum samples were collected at 24, 48, and $72 \mathrm{~h}$ after enrolment in the study and were processed at the study sites, aliquoted and frozen to $-80^{\circ} \mathrm{C}$ before shipment to the Integrated Biobank of Luxemburg. Centralized batch analysis of copeptin was done using immune fluorescence with the Brahms Kryptor Compact Plus system (Thermo Fisher Scientific Brahms, Germany), with range of $0.7-500 \mathrm{pmol} / \mathrm{L}$ (auto dilution with upper range of $2000 \mathrm{pmol} / \mathrm{L}$ ) and functioning assay sensitivity of $1.08 \mathrm{pmol} / \mathrm{L}$. All serum samples with interference detected by the Kryptor system were discarded. Analyses of copeptin were made at least 6 months after trial completion.

\section{Outcomes}

The primary outcome was incidence of death until 30 days after enrolment in the TTM trial. The secondary endpoints were circulatory cause of death within 30 days of cardiac arrest, as estimated from clinical data, and the extended cardiovascular sequential organ failure assessment score (eCvSOFA), a nine level sub-score of the SOFA cardiovascular component [19]. In addition, we devised a binary composite outcome of cardiovascular deterioration (cardiovascular deterioration composite $(\mathrm{CvDC}))$ considered positive if the patient had an $\mathrm{eCv}$ SOFA $\geq 5$ or died from circulatory cause at within $\pm 12 \mathrm{~h}$ 
of copeptin sample or if eCvSOFA score increased more than two points within the previous $24 \mathrm{~h}$.

\section{Statistical analysis}

Descriptive statistics were used to summarize the study population. Continuous data are presented as median with interquartile range. Differences in baseline variables were assessed using the Mann-Whitney or the $\chi^{2}$ test, as appropriate. Analyses were primarily performed on 24-h samples of copeptin, with the secondary analyses performed on serial samples (48, 72-h samples). No formal adjustment of significance levels due to multitesting was performed. Due to missingness in the dataset, analyses were performed on a pooled dataset for the explanatory models based on 20 imputations by chained equations, using predictive mean matching for continuous variables and logistic regression for categorical data. Because of skewed distribution of copeptin data, log2-transformed copeptin levels were used in Cox and logistic regression models. All models were adjusted for TTM at $33^{\circ} \mathrm{C}$ (yes/no) and early clinical predictors of outcome according to the TTM-score [20]: age (years), cardiac arrest at home (yes/no), no-flow time (minutes from cardiac arrest until start of chest compressions or ROSC,

Table 1 Baseline characteristics

\begin{tabular}{|c|c|}
\hline Characteristic & Patients included in sub-study \\
\hline Subjects & 690 \\
\hline Temperature intervention at $36 \mathrm{C}, n=690$ & $343(49.7)$ \\
\hline Age, years, $n=690$ & $65[56-73]$ \\
\hline Male sex, $n=690$ & $558(80.9)$ \\
\hline \multicolumn{2}{|l|}{ Previous medical history } \\
\hline Myocardial infarction, $n=684$ & $134(19.6)$ \\
\hline Ischemic heart disease, $n=683$ & $187(27.4)$ \\
\hline Arrhythmia, $n=684$ & $121(17.7)$ \\
\hline Arterial hypertension, $n=682$ & $277(40.6)$ \\
\hline Diabetes, $n=679$ & $100(14.7)$ \\
\hline \multicolumn{2}{|l|}{ Intra-arrest characteristics } \\
\hline Witnessed cardiac arrest, $n=687$ & $614(89.4)$ \\
\hline Cardiac arrest at home, $n=690$ & $364(52.8)$ \\
\hline Bystander cardiopulmonary resuscitation, $n=690$ & $499(72.3)$ \\
\hline No flow time $(\min ), n=679$ & $1[0-5]$ \\
\hline Low flow time (min), $n=679$ & $22[14-35]$ \\
\hline Dose of adrenaline $(\mathrm{mg}), n=680$ & $2[0-4]$ \\
\hline ST-elevation myocardial infarction, $n=676$ & $276(40.8)$ \\
\hline \multicolumn{2}{|l|}{ First monitored rhythm, $n=690$} \\
\hline Non shockable & $128(18.6)$ \\
\hline Shockable & $542(78.6)$ \\
\hline Unknown & $20(2.9)$ \\
\hline \multicolumn{2}{|l|}{ Early hospital characteristics } \\
\hline Moderate shock on admission, $n=686$ & $85(12.4)$ \\
\hline Lactate at admission ( $\mathrm{mmol} / \mathrm{l}), n=619$ & $5.9[3.2-9.3]$ \\
\hline Admission $\mathrm{pCO}_{2}<4.5 \mathrm{kPa}, n=645$ & $80(11.6)$ \\
\hline Pupillary or corneal reflexes present on admission, $n=649$ & $7.23[7.13-7.31]$ \\
\hline Admission GCSm $>1$ or sedated, $n=679$ & $308(44.6)$ \\
\hline Pupillary or corneal reflexes present on admission, $n=655$ & $527(76.4)$ \\
\hline Extended cardiovascular SOFA score day 1, $n=673$ & $3[2-4]$ \\
\hline Positive cardiovascular deterioration composite at $24 \mathrm{~h}, n=670$ & $203(30.3 \%)$ \\
\hline
\end{tabular}

Baseline characteristics in the TTM biobank population included in the analysis. Continuous data is presented as median value with interquartile range, while categorical data as number of subjects and percentages. $n$ represents the total number of samples available for analysis 
whichever was first), low-flow time (minutes with chest compressions), shockable rhythm (yes/no), use of adrenaline during CPR (yes/no), absence of corneal and pupillary reflexes on admission (yes/no), Glasgow coma score motor component (mGCS) on admission $>1$ or sedated (yes/no), admission $\mathrm{pH}$, and admission $\mathrm{PaCO}_{2}<$ $4.5 \mathrm{kPa}$ (yes/no). The log-rank test was used to test for difference in 30-day survival according to copeptin levels stratified as above or below median at the specified time point in the biobank population and visualized in Kaplan-Meier graphs. Adjusted hazard ratio for death was estimated using the Cox regression of proportional hazards model, with follow-up time censored at 30 days. Multivariate logistic regression was performed for circulatory cause of death. Correlation between copeptin and eCvSOFA-score was assessed using Spearman's rank order correlation. Multivariate logistic regression was performed for CvDC.

A sensitivity analysis was performed comparing the results of a complete cases adjusted Cox regression model for the primary endpoint at 24,48 , and $72 \mathrm{~h}$ with that of the imputed model.

Statistical analysis was performed using software R ( $\mathrm{v}$ 3.4.0) and RStudio (v 1.0.143).

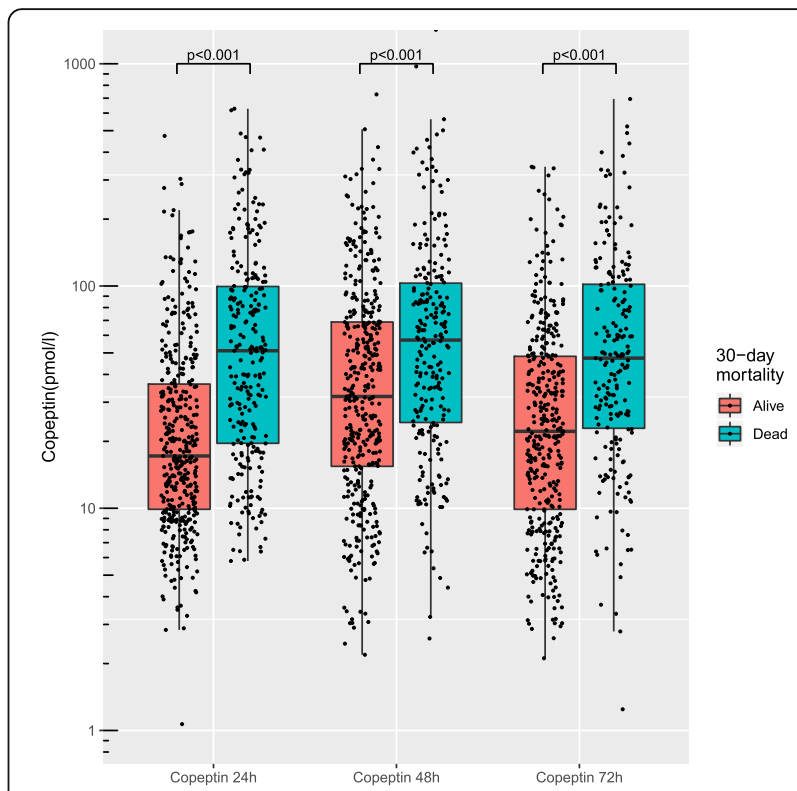

Fig. 1 Copeptin levels stratified according to 30-day mortality. Box plot illustrating difference in copeptin levels measured at 24,48 , and $72 \mathrm{~h}$ after cardiac arrest in survivors vs non-survivors at day 30 . Copeptin on $Y$-axis is on a log scale

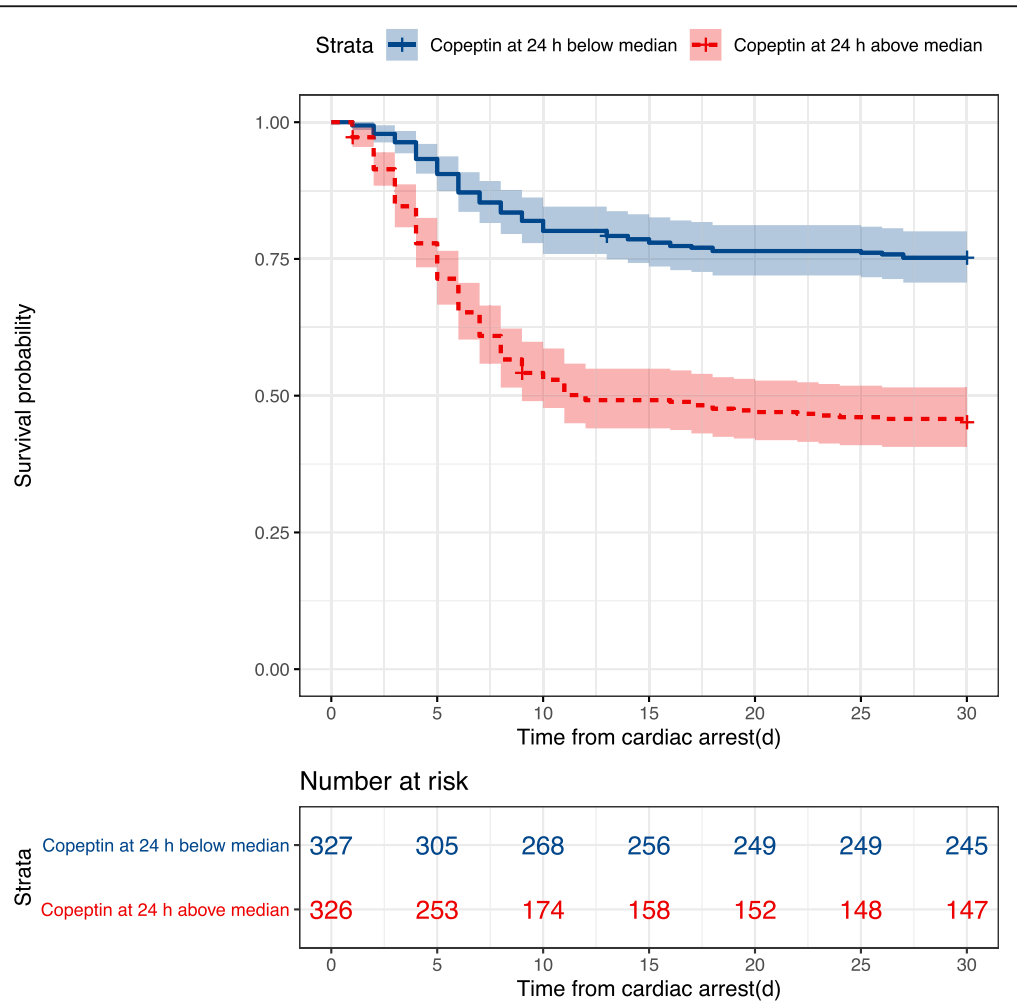

Fig. 2 Probability of 30-day survival. Kaplan-Meier graph illustrating the probability of survival after cardiac arrest according to copeptin levels stratified as above or below median at $24 \mathrm{~h}$. Outcome was censored after 30 days. Shaded areas indicate $95 \%$ confidence interval. Survival was significantly higher in the group with copeptin levels below median at $24 \mathrm{~h}, p<0.001$ 


\section{Results}

A total of 690 patients were included in this TTM biobank sub-study (Table 1). Of 2070 possible copeptin values, $112(5.4 \%)$ were missing, $53(2.6 \%)$ because of death prior to sampling (Additional file 1).

\section{Copeptin and temperature}

Differences in copeptin levels between interventions were highest at $72 \mathrm{~h}, 33.00[15.76-63.62]$ for $33^{\circ} \mathrm{C}$ and $26.46[11.37-59.28] \quad \mathrm{pmol} / \mathrm{l}, \quad$ for $36^{\circ} \mathrm{C}, \quad p=0.049$ (Additional file 2). Copeptin levels increased more between $24 \mathrm{~h}$ and $48 \mathrm{~h}$ at an intervention of $33^{\circ} \mathrm{C}, 6.11$ [4.25-36.96] compared to $36^{\circ} \mathrm{C} 1.91$ [-9.51-27.38] $\mathrm{pmol} / \mathrm{l},(p=0.026)$, while no significant differences were seen between 48 and $72 \mathrm{~h}$. Since differences between intervention arms were minor and our primary aim was to test associations between copeptin and outcome, all further analyses were performed on pooled samples.

\section{Copeptin and mortality}

Two hundred seventy-three (39.6\%) patients died within 30 days. Copeptin levels were significantly lower in survivors than in patients dead by day 30 , at $24 \mathrm{~h} 17.19$ [9.89-36.20] versus 51.14 [19.60-99.51] pmol/l, at $48 \mathrm{~h}$ 31.84 [15.44-59.49] versus 57.11 [24.32-102.97] pmol/l, and at $72 \mathrm{~h} 22.19$ [9.89-48.26] versus 47.37 [22.90101.78] pmol/l, all $p$ values $<0.001$ (Fig. 1). Crude 30day survival was associated with copeptin stratified as above or below median at $24 \mathrm{~h}, p<0.001$ (Fig. 2), at $48 \mathrm{~h}$, $p=0.001$, and $72 \mathrm{~h} p<0.001$ (Additional file 3). The incidence of death was independently associated with $\log 2-$ transformed copeptin, hazard ratio (HR) 1.17 [1.061.28], $p=0.001$ (Fig. 3); for samples at $24 \mathrm{~h}$, significance was lost at $48 \mathrm{~h}, p=0.471$, while 72 -h samples were trending towards significance, HR 1.11 [1.00-1.23], $p=0.054$.

\section{Copeptin and circulatory failure}

In the adjusted model, log2-transformed copeptin was independently associated with circulatory cause of death, at $24 \mathrm{~h}$, with an odds ratio (OR) of 1.03 [1.01-1.04], $p=$ 0.001 (Additional file 4). The Spearman rank order correlation between eCvSOFA and copeptin, rho, was 0.19 [0.12-0.27] at $24 \mathrm{~h}, 0.22[0.14-0.29]$ at $48 \mathrm{~h}$ and 0.26 [0.18-0.34] at $72 \mathrm{~h}, p<0.001$, for all time points. Log2transformed copeptin was independently associated with cardiovascular deterioration with OR 1.05 [1.02-1.08], $p<0.001$ at $24 \mathrm{~h}$ (Fig. 4); OR 1.03 [1.00-1.05], $p=0.021$ at $48 \mathrm{~h}$; and OR 1.03 [1.01-1.06], $p=0.016$ at $72 \mathrm{~h}$.

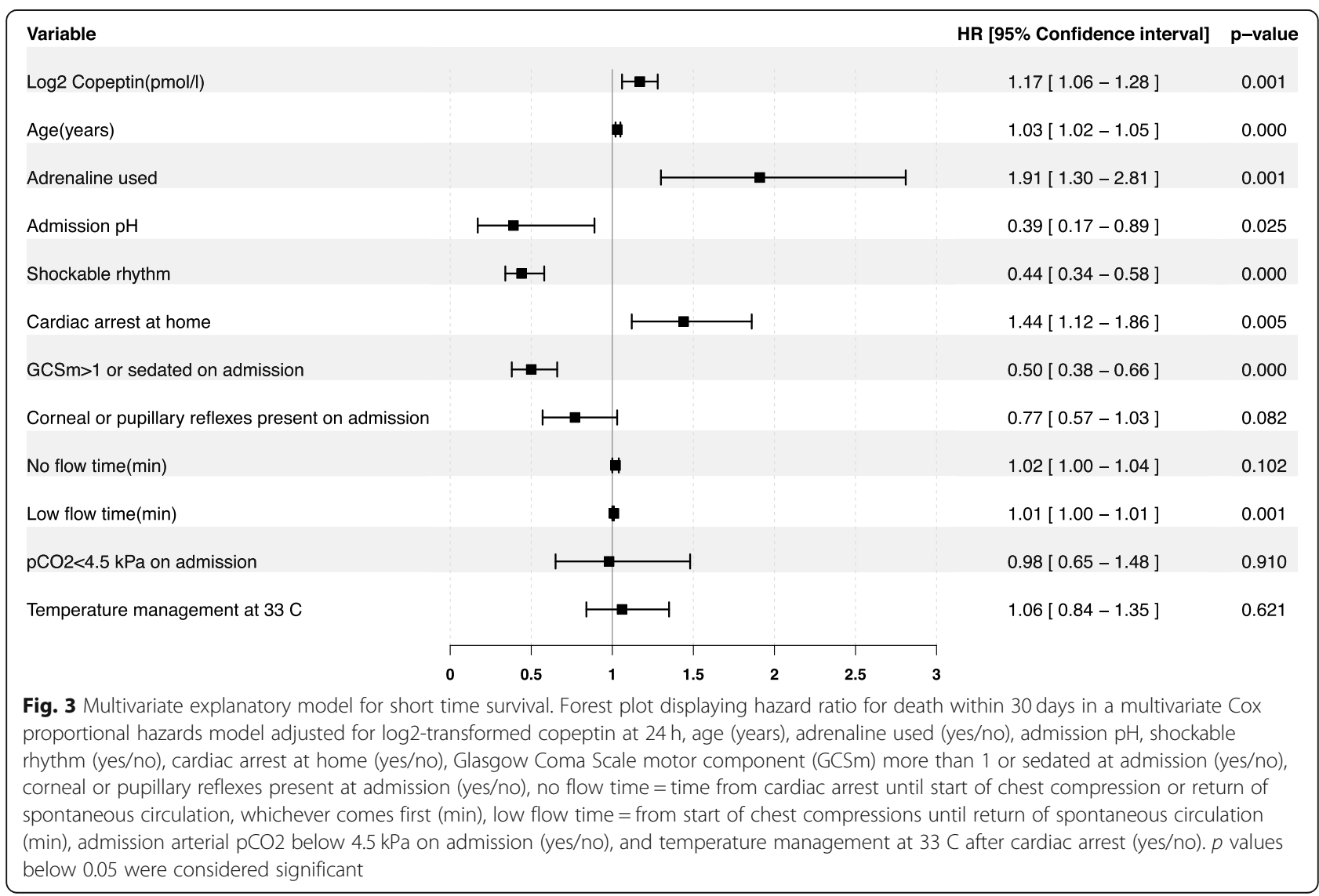




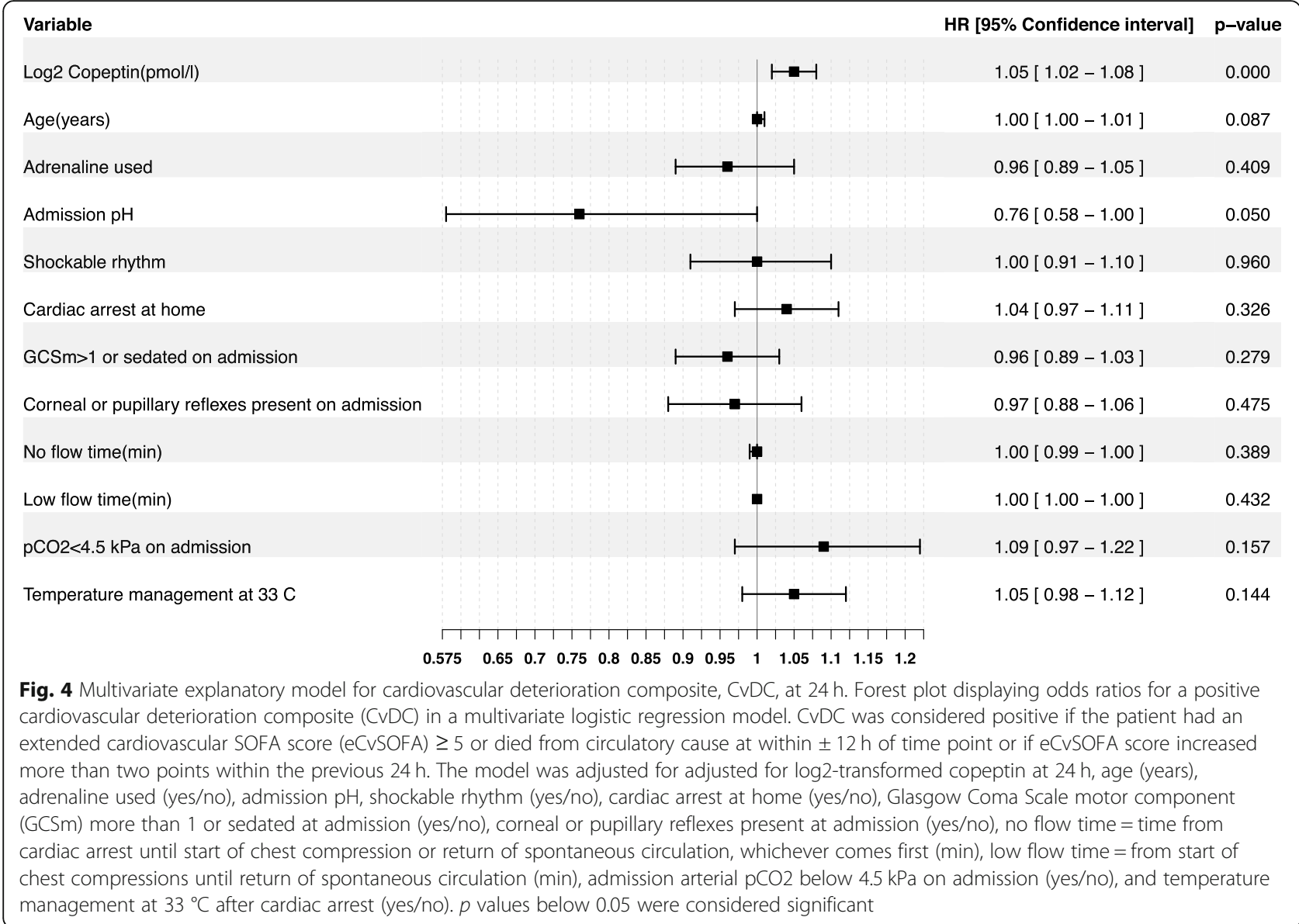

In the sensitivity analysis, results from the Cox regression models on imputed datasets and observed data were similar (data not shown).

\section{Discussion}

The main findings of this sub-study of the TTM trial were that copeptin is a time sensitive, independent predictor of early mortality after OHCA, weakly associated with cardiovascular failure.

This is to date the largest study investigating copeptin as a marker of outcome after OHCA. Our finding that copeptin was associated with outcome is in agreement with previous studies [13-16, 21, 22]. Studies by Annborn et al. [13, 16] and Broessner et al. [14] indicate better prognostic precision with early measurements of copeptin which could be one reason for copeptin being significantly associated with survival at $24 \mathrm{~h}$ only, in our multivariate analysis. Previous studies have indicated a rapid release and clearance of copeptin [23] after circulatory stress, and this may explain why early copeptin levels would be more strongly associated with early mortality. Copeptin was associated with temperature change, and the multivariate analyses are adjusted for TTM, but it cannot be ruled out that the temperature intervention might have confounded the results of the $48 \mathrm{~h}$ analysis, since the patients in the intervention group with TTM at $33{ }^{\circ} \mathrm{C}$ were rewarmed to $37^{\circ} \mathrm{C}$ between 28 and $36 \mathrm{~h}$ according to the TTM trial protocol. Death before sampling is a potential confounder that decreased our results for copeptin's association with death, as these patients probably had high copeptin levels.

As the results of this study indicate an association between early mortality, circulatory status and circulatory cause of death with high early copeptin levels, it seems reasonable to expect that the exclusion of patients with severe hemodynamic shock may have decreased the prognostic precision of copeptin. Since exclusion due to irreversible severe shock in the TTM trial was $2 \%$, we believe this effect, however, to be minor.

Copeptin was independently associated with circulatory endpoints and associated with early mortality in univariate analysis at 24, 48, and $72 \mathrm{~h}$, while copeptin was independently associated with short time survival at $24 \mathrm{~h}$. This might indicate copeptin to represent the composite stress due to a wide array of pathologies, e.g., hypoxia, shock, and infection, rather than to represent circulatory failure alone. This is consistent with copeptin being associated with outcome in various other settings, 
such as pneumonia, stroke, postoperative trauma, and traumatic brain injury [4, 24-26].

The association of copeptin with $\mathrm{CvDC}$ was significant at all time points with modest ORs, which is consistent with the low correlation with eCvSOFA. We did not account for multitesting, but since $p$ values were consistently low, we believe copeptin is a true, albeit not clinically relevant, indicator of circulatory status. The independent association of copeptin with circulatory cause of death at $24 \mathrm{~h}$, but not 48 or $72 \mathrm{~h}$, should thus be interpreted cautiously.

The use of copeptin as a clinical screening tool to identify OHCA patients who might benefit from extended hemodynamic monitoring cannot be supported by our results, primarily because copeptin is not associated with circulatory status at any clinically relevant level. Further studies on copeptin are needed to clarify the optimal timing of sampling, the potential value as a marker of circulatory failure or a marker of disease severity in early multivariate prognostic models, including comparisons to other relevant biomarkers (e.g., natriuretic peptides, C-reactive protein, and procalcitonin). Furthermore, more research is warranted to investigate the complex interactions of copeptin as a marker of free water resorption, vasopressor, and cortisol status in the critically injured patient.

\section{Strengths and limitations}

This is a large predefined sub-study of the TTM trial investigating copeptin as a marker of severity of the post cardiac arrest syndrome. The TTM trial had strict rules for withdrawal of life-sustaining therapy, and all clinical data were prospectively collected. Analyses were made in a single laboratory, limiting the risk of interlaboratory assay variability, and copeptin values were analyzed after trial completion, eliminating the risk of treatment bias. Due to the limitations of an observational study, we can however only assess associations with outcome. It cannot be ruled out that missing data may have affected our results. The collection of blood samples for the biobank of the TTM trial was not specifically designed for this sub-study, and the initial sampling of copeptin at $24 \mathrm{~h}$ may have been too late for optimal assessment of associations with outcome and circulatory derangement. Patients dying before $24 \mathrm{~h}$ were excluded from our analysis, limiting our results to patients alive at $24 \mathrm{~h}$; also, the exclusion of patients in irreversible hemodynamic shock may limit the generalizability of our results.

\section{Conclusion}

Copeptin is an independent marker of severity of the post cardiac arrest syndrome, partially related to circulatory failure.

\section{Supplementary information}

Supplementary information accompanies this paper at https://doi.org/10. 1186/s13054-020-02904-8.

Additional file 1. Flow chart. A, the number of patients enrolled in the TTM-trial and included in the sub-study. B, Illustrates missing copeptin data within $72 \mathrm{~h}$

Additional file 2. Boxplot illustrating difference in copeptin levels measured at 24, 48, and $72 \mathrm{~h}$ after cardiac arrest in patients treated with a temperature intervention at $33 \mathrm{C}$ or $36 \mathrm{C}$. Copeptin on Y-axis is on a log scale. TTM: Targeted Temperature Management.

Additional file 3. Kaplan-Meier plots according to copeptin levels stratified as above or below median at 48 , and $72 \mathrm{~h}$. Shaded areas indicate $95 \%$ confidence interval. Outcome was censored after 30 days. Survival was significantly higher in the group with copeptin levels below median at $48 \mathrm{~h}, p=0.001$ and $72 \mathrm{~h}, p<0.001$.

Additional file 4. Forest plot displaying odds ratios for cardiac cause of death within 30 days of cardiac arrest in a multivariate logistic regression mode. The model is adjusted for adjusted for: log2 transformed copeptin at $24 \mathrm{~h}$, age (years), adrenaline used (yes/no), admission pH, Shockable rhythm (yes/no), cardiac arrest at home (yes/no), Glasgow Coma Scale motor component (GCSm) more than 1 or sedated at admission (yes/no), corneal or pupillary reflexes present at admission (yes/no), no flow time $=$ time from cardiac arrest until start of chest compression or return of spontaneous circulation, whichever comes first (min), low flow time = from start of chest compressions until return of spontaneous circulation (min), admission arterial pCO2 below $4.5 \mathrm{kPa}$ on admission (yes/no), and temperature management at $33 \mathrm{C}$ after cardiac arrest (yes/no). $p$-values below 0.05 were considered significant.

\section{Abbreviations}

WLST: Withdrawal of life-sustaining therapy; TTM: Targeted temperature management; SOFA: Systemic organ failure assessment; eCvSOFA: Extended cardiovascular systemic organ failure assessment; HIE: Hypoxic ischemic encephalopathy; OHCA: Out-of-hospital cardiac arrest; AVP: Arginine vasopressin; CT-proAVP: C-terminal pro-arginine vasopressin (copeptin); ROSC: Return of spontaneous circulation; SBP: Systolic blood pressure; CvDC: Cardiovascular deterioration composite; CPC: Cerebral performance category; mGCS: Motor component of Glasgow Coma Score; STEMI: STelevation myocardial infarction; HR: Hazard ratio; OR: Odds ratio

\section{Acknowledgements}

Analyses of copeptin were made free of charge by Thermo-Fisher Scientific Inc.

\section{Authors' contributions}

JDü: Design and writing of manuscript, analysis/interpretation of data. MA: Design of manuscript, analysis/interpretation of data. Substantial revision of manuscript. TC: Interpretation of data. Substantial revision of manuscript. JDa: Interpretation of data. Substantial revision of manuscript. YD: Interpretation of data. Substantial revision of manuscript. $\mathrm{CH}$ : Interpretation of data. Substantial revision of manuscript. JH: Interpretation of data. Substantial revision of manuscript. JK: Interpretation of data. Substantial revision of manuscript. MK: Interpretation of data. Substantial revision of manuscript. HRN: Interpretation of data. Substantial revision of manuscript. PS: Interpretation of data. Substantial revision of manuscript. JU: Interpretation of data. Substantial revision of manuscript. MW: Interpretation of data. Substantial revision of manuscript. MJW: Interpretation of data. Substantial revision of manuscript. HF: Design of manuscript, analysis/interpretation of data. Substantial revision of manuscript. NN: Design of manuscript, analysis/ interpretation of data. Substantial revision of manuscript. The authors read and approved the final manuscript.

\section{Authors' information}

Not applicable

\section{Funding}

Funding for the study was provided by the Swedish Research Council (grants 134281, 296161, 286321); Swedish Heart Lung Foundation (grant 
20090275); Arbetsmarknadens Försäkringsaktiebolag (grant 100001); Skåne University Hospital Foundations, the Gyllenstierna-Krapperup Foundation, and governmental funding of clinical research within the Swedish National Health System (grants M2010/1837, M2010/1641, 353301); The County Council of Skåne; The Swedish Society of Medicine; The Koch Foundation; TrygFonden (Denmark); Lundbeck Foundation (R186-2015-2132), European Clinical Research Infrastructures Network; Thelma Zoega Foundation; Stig and Ragna Gorthon Foundation; Thure Carlsson Foundation; Hans-Gabriel and Alice Trolle-Wachtmeister Foundation for Medical Research; Lions Research fund Skåne; South Swedish Hospital Region Research Funds (Södra Sjukvårdsregionen Regionalt Forskningsstöd); The Swedish Brain Foundation; and The Torsten Söderberg foundation at the Royal Swedish Academy of Sciences.

The funding organizations had no role in the design and conduct of the study, collection, management, analysis, interpretation of the data, preparation, review, approval of the manuscript, or decision to submit the manuscript for publication. Open access funding provided by Lund University.

\section{Availability of data and materials}

The data that support the findings of this study are available from Niklas Nielsen, but restrictions apply to the availability of these data, which were used under license for the current study, and so are not publicly available. Data are however available from the authors upon reasonable request and with permission of Niklas Nielsen.

\section{Ethics approval and consent to participate}

The TTM trial protocol was approved by ethical committees in each participating country, and informed consent was waived or obtained from all participants or relatives according to national legislations, in line with the Helsinki declaration. Ethical Review Board approval, REPN Lund Dnr 2009/ 324.

\section{Consent for publication}

Not applicable

\section{Competing interests}

HF: Bard Medical (lecture fees), QuickCool (scientific advisor). HRN: Medical Director at Thermo Fisher Scientific. YD: Funds from; National Research Fund of Luxembourg (grants \# C14/BM/ 8225223 and C17/BM/11613033), The Ministry of Higher Education and Research of Luxembourg and The Heart Foundation - Daniel Wagner. MW: BARD Medical (2009: Advisory board). BARD Medical (2018: Lecture, accommodation and travel fees).

JK: Research on management of post cardiac arrest care supported by the NovoNordisk Foundation (NNF17OC0028706).

\section{Author details}

'Department of Clinical Sciences, Anesthesia \& Intensive care, Lund University, Skåne University Hospital, Malmö, Sweden. ${ }^{2}$ Department of Clinical Sciences Lund, Anesthesia \& Intensive care, Lund University, Helsingborg Hospital, Helsingborg, Sweden. ${ }^{3}$ Department of Clinical Sciences, Neurology, Lund University, Skåne University Hospital, Lund, Sweden. ${ }^{4}$ Department of Clinical Sciences, Cardiology, Lund University, Skåne University Hospital, Lund, Sweden. ${ }^{5}$ Cardiovascular Research Unit, Luxembourg Institute of Health, Strassen, Luxembourg. ${ }^{6}$ Department of Cardiology, Rigshospitalet and Dept of Clinical Medicine, University of Copenhagen, Copenhagen, Denmark. ${ }^{7}$ Department of Intensive Care, Amsterdam UMC, University of Amsterdam, Amsterdam, The Netherlands. ${ }^{8}$ Department of Intensive Care, Medical Center Leeuwarden, Leeuwarden, The Netherlands. ${ }^{9}$ Thermo Fisher Scientific, Asnières sur Seine, France. ${ }^{10}$ Medical and Health Directorate, National Fire and Rescue Corps, 1, rue Stümper, 2557 Luxembourg, Luxembourg. ${ }^{11}$ Department of Clinical Sciences Lund, Anesthesia \& Intensive care, Lund University, Halmstad Hospital, Halmstad, Sweden. ${ }^{12}$ Department of Cardiothorasic anesthesia, Rigshospitalet and Dept of Clinical medicine, University of Copenhagen, Copenhagen, Denmark. ${ }^{13}$ Adult Critical Care, University Hospital of Wales, Cardiff, UK.
Received: 14 December 2019 Accepted: 16 April 2020 Published online: 28 April 2020

\section{References}

1. Laver S, Farrow C, Turner D, Nolan J. Mode of death after admission to an intensive care unit following cardiac arrest. Intensive Care Med. 2004;30(11): 2126-8.

2. Dragancea I, Rundgren M, Englund E, Friberg $H$, Cronberg T. The influence of induced hypothermia and delayed prognostication on the mode of death after cardiac arrest. Resuscitation. 2013;84(3):337-42.

3. Bascom KE, Dziodzio J, Vasaiwala S, Mooney M, Patel N, McPherson J, McMullan P, Unger B, Nielsen N, Friberg H, et al. Derivation and validation of the CREST model for very early prediction of circulatory etiology death in patients without ST-segment-elevation myocardial infarction after cardiac arrest. Circulation. 2018;137(3):273-82.

4. Jochberger S, Zitt M, Luckner G, Mayr VD, Wenzel V, Ulmer H, Morgenthaler NG, Hasibeder WR, Dunser MW. Postoperative vasopressin and copeptin levels in noncardiac surgery patients: a prospective controlled trial. Shock. 2009;31(2):132-8.

5. Kim JJ, Hyun SY, Hwang SY, Jung YB, Shin JH, Lim YS, Cho JS, Yang HJ, Lee $\mathrm{G}$. Hormonal responses upon return of spontaneous circulation after cardiac arrest: a retrospective cohort study. Crit Care. 2011;15(1):R53.

6. Lindner KH, Haak T, Keller A, Bothner U, Lurie KG. Release of endogenous vasopressors during and after cardiopulmonary resuscitation. Heart. 1996; 75(2):145-50.

7. Imamura T, Kinugawa K, Hatano M, Fujino T, Inaba T, Maki H, Kinoshita O, Nawata K, Kyo S, Ono M, et al. Low cardiac output stimulates vasopressin release in patients with stage d heart failure. Circ J. 2014;78(9):2259-67.

8. Morgenthaler NG, Struck J, Alonso C, Bergmann A. Assay for the measurement of copeptin, a stable peptide derived from the precursor of vasopressin. Clin Chem. 2006;52(1):112-9.

9. Keller T, Tzikas S, Zeller T, Czyz E, Lillpopp L, Ojeda FM, Roth A, Bickel C, Baldus $S$, Sinning $C R$, et al. Copeptin improves early diagnosis of acute myocardial infarction. J Am Coll Cardiol. 2010;55(19):2096-106.

10. Zhong Y, Wang R, Yan L, Lin M, Liu X, You T. Copeptin in heart failure: review and meta-analysis. Clin Chim Acta. 2017;475:36-43.

11. Voors AA, von Haehling S, Anker SD, Hillege HL, Struck J, Hartmann O, Bergmann A, Squire I, van Veldhuisen DJ, Dickstein K, et al. C-terminal provasopressin (copeptin) is a strong prognostic marker in patients with heart failure after an acute myocardial infarction: results from the OPTIMAAL study. Eur Heart J. 2009;30(10):1187-94.

12. Wildi $K$, Zellweger $C$, Twerenbold $R$, Jaeger $C$, Reichlin $T$, Haaf $P$, Faoro J, Gimenez MR, Fischer A, Nelles B, et al. Incremental value of copeptin to highly sensitive cardiac Troponin I for rapid rule-out of myocardial infarction. Int J Cardiol. 2015;190:170-6.

13. Annborn M, Dankiewicz J, Nielsen N, Rundgren M, Smith JG, Hertel S, Struck J, Friberg H. CT-proAVP (copeptin), MR-proANP and Peroxiredoxin 4 after cardiac arrest: release profiles and correlation to outcome. Acta Anaesthesiol Scand. 2014;58(4):428-36.

14. Broessner $G$, Hasslacher J, Beer R, Lackner P, Lehner GF, Harler U, Schiefecker A, Helbok R, Pfausler B, Hammerer-Lercher A, et al. Outcome prediction and temperature dependency of MR-proANP and Copeptin in comatose resuscitated patients. Resuscitation. 2015;89:75-80.

15. Ostadal P, Kruger A, Zdrahalova V, Janotka M, Vondrakova D, Neuzil P, Prucha M. Blood levels of copeptin on admission predict outcomes in outof-hospital cardiac arrest survivors treated with therapeutic hypothermia. Crit Care. 2012;16(5):R187.

16. Annborn M, Nilsson F, Dankiewicz J, Rundgren M, Hertel S, Struck J, Cronberg T, Nielsen N. The combination of biomarkers for prognostication of long-term outcome in patients treated with mild hypothermia after outof-hospital cardiac arrest-a pilot study. Ther Hypothermia Temp Manag. 2016;6(2):85-90.

17. Nielsen N, Wetterslev J, Cronberg T, Erlinge D, Gasche Y, Hassager C, Horn J, Hovdenes J, Kjaergaard J, Kuiper M, et al. Targeted temperature management at 33 degrees $C$ versus 36 degrees $C$ after cardiac arrest. N Engl J Med. 2013;369(23):2197-206.

18. Williams JR. The Declaration of Helsinki and public health. Bull World Health Organ. 2008;86(8):650-2.

19. Annborn M, Bro-Jeppesen J, Nielsen N, Ullen S, Kjaergaard J, Hassager C, Wanscher M, Hovdenes J, Pellis T, Pelosi P, et al. The association of targeted temperature management at 33 and 36 degrees $C$ with outcome in 
patients with moderate shock on admission after out-of-hospital cardiac arrest: a post hoc analysis of the target temperature management trial. Intensive Care Med. 2014;40(9):1210-9.

20. Martinell L, Nielsen N, Herlitz J, Karlsson T, Horn J, Wise MP, Unden J, Rylander C. Early predictors of poor outcome after out-of-hospital cardiac arrest. Crit Care. 2017;21(1):96.

21. Ristagno G, Latini R, Plebani M, Zaninotto M, Vaahersalo J, Masson S, Tiainen M, Kurola J, Gaspari F, Milani V, et al. Copeptin levels are associated with organ dysfunction and death in the intensive care unit after out-of-hospital cardiac arrest. Crit Care. 2015;19:132.

22. Geri G, Dumas F, Chenevier-Gobeaux C, Bougle A, Daviaud F, MorichauBeauchant T, Jouven X, Mira JP, Pene F, Empana JP, et al. Is copeptin level associated with 1-year mortality after out-of-hospital cardiac arrest? Insights from the Paris registry*. Crit Care Med. 2015;43(2):422-9.

23. D'Onofrio A, Russo V, Bianchi V, Cavallaro C, Leonardi S, De Vivo S, Vecchione F, Rago A, Ammendola E, Tavoletta V, et al. Effects of defibrillation shock in patients implanted with a subcutaneous defibrillator: a biomarker study. Europace. 2018;20(F/2):f233-9.

24. Xu Q, Tian Y, Peng H, Li H. Copeptin as a biomarker for prediction of prognosis of acute ischemic stroke and transient ischemic attack: a metaanalysis. Hypertens Res. 2017;40(5):465-71.

25. Choi KS, Cho Y, Jang BH, Kim W, Ahn C, Lim TH, Yi HJ. Prognostic role of copeptin after traumatic brain injury: a systematic review and meta-analysis of observational studies. Am J Emerg Med. 2017;35(10):1444-50.

26. Viasus D, Del Rio-Pertuz G, Simonetti AF, Garcia-Vidal C, Acosta-Reyes J, Garavito A, Carratalà J. Biomarkers for predicting short-term mortality in community-acquired pneumonia: a systematic review and meta-analysis. J Infect. 2016;72(3):273-82.

\section{Publisher's Note}

Springer Nature remains neutral with regard to jurisdictional claims in published maps and institutional affiliations.

Ready to submit your research? Choose BMC and benefit from:

- fast, convenient online submission

- thorough peer review by experienced researchers in your field

- rapid publication on acceptance

- support for research data, including large and complex data types

- gold Open Access which fosters wider collaboration and increased citations

- maximum visibility for your research: over $100 \mathrm{M}$ website views per year

At $\mathrm{BMC}$, research is always in progress.

Learn more biomedcentral.com/submissions 